\title{
The Novel Effect of Immunomodulator- Glatiramer Acetate on Epileptogenesis and Epileptic Seizures
}

\author{
Ming-Chi Lai ${ }^{\mathrm{a}}$ Kao-Min Lin ${ }^{\mathrm{b}}$ Poh-Shiow Yeh ${ }^{\mathrm{c}}$ Sheng-Nan Wu \\ Chin-Wei Huange \\ aDepartment of Pediatrics, Chi-Mei Medical Center, Tainan, bepartment of Pediatric Neurology, Chiayi \\ Christian Hospital, Chiayi, 'Department of Neurology, Chi-Mei Medical Center, Tainan, ${ }^{d}$ Department of \\ Physiology, National Cheng Kung University, College of Medicine, National Cheng Kung University, \\ Tainan, eDepartment of Neurology, National Cheng Kung University Hospital, College of Medicine, \\ National Cheng Kung University, Tainan, Taiwan
}

\section{Key Words}

Glatiramer acetate $\bullet$ Seizure $\bullet$ Epilepsy $\bullet$ Sodium- channel $\bullet$ Interleukin- $1 \cdot$ Neuron

\begin{abstract}
Background/Aims: Immunological mechanisms can be triggered as a response to central nervous system insults and can lead to seizures. In this study an investigation was made to determine if glatiramer acetate (GA), an immunomodulator currently used in the treatment of multiple sclerosis, could protect rats from pilocarpine-induced seizures and chronic epilepsy. Methods: Two groups of adult male Sprague-Dawley rats, experimental (GA) and control, were used in the study. The systemic IL- $1 \alpha$ and IL-1 $\beta$ levels at baseline were checked as well as status epilepticus (SE), and the spontaneous recurrent seizure (SRS) stage by enzymelinked immunosorbent assay. The GA group was given GA $(150 \mu \mathrm{g} / \mathrm{kg}$, ip) and the control group was given a saline injection prior to pilocarpine-induced seizures. Seizure susceptibility, severity and mortality were evaluated, using Racine seizure classification and hippocampal damage was evaluated by Nissl staining. The GA group received GA (150 $\mu \mathrm{g} / \mathrm{kg} / \mathrm{day}$, ip) daily after $\mathrm{SE}$, and the chronic spontaneous seizures were evaluated by long-term video recording, and mossy fiber sprouting was evaluated by Timm staining. The IL-1 $\alpha$ and IL-1 $\beta$ levels were correlated with seizure activities. The TNF- $\alpha$ level in the hippocampus was determined at the SRS stage by immunohistochemistry. The effect of GA on ionic currents and action potentials (APs) in NG108-15 differentiated neurons was investigated using patch-clamp technology. Results: It was found that latency to severe seizures was significantly longer in the GA ( $p$ $<0.01)$ group, which also had SE of shorter duration and less frequent SRS ( $p<0.01)$. GA attenuated acute hippocampal neuron loss and chronic mossy fiber sprouting in the CA3 and the SRS-reduction correlated with the reduction of IL- $1 \alpha$, but not with IL-1 $\beta$ or TNF- $\alpha$ levels. Mechanistically, GA reduced the peak amplitude of voltage-gated $\mathrm{Na}^{+}$current $\left(I_{\mathrm{Na}}\right)$, with a negative shift in the inactivation curve of $I_{\mathrm{Na}}$ and reduced the amplitude of APs along with

\begin{tabular}{ll}
\hline Chin-Wei Huang & Department of Neurology, National Cheng Kung University Hospital, College of \\
& Medicine, National Cheng Kung University, Tainan (Taiwan) \\
& Tel. 886-6-2353535, E-Mail huangcw@mail.ncku.edu.tw
\end{tabular}
\end{abstract}


Lai et al.: Effect of Glatiramer Acetate on Epileptogenesis and Seizures

decreased firing of APs. Conclusion: GA might serve as a neuroexcitability modulator which attenuates pilocarpine-induced acute and chronic excitotoxicity. Sodium channel attenuation was partially independent of the immunomodulatory effect.

\section{Introduction}

Epilepsy is a chronic neurological disorder that affects approximately $1 \%$ of the population globally. Although great advances have been made in the development of new antiepileptic drugs (AED)s, one-third of patients remain refractory to existing AED treatment [1]. The current AEDs, although they have anticonvulsant properties, generally lack definite disease-modifying and anti-epileptogenic properties [2]. Therefore, despite the beneficial effect of the currently available AEDs, there is still a need for novel drugs with antiepileptogenic properties.

It is known that both innate and adaptive immunity can be triggered in response to central nervous system (CNS) insults and lead to seizures [3]. Both brain inflammatory activation and blood-brain barrier dysfunction could initiate seizures [4]. Studies have also reported reactive gliosis in pilocarpine-induced epilepsy $[5,6]$ and increased expression of mRNA for interleukin IL-1 $\beta$, IL-6, iNOS and tumor necrosis factor (TNF)- $\alpha$ after seizures [7]. The chronic inflammation-related glial scar, generally regarded as epileptogenic, is involved in axonal sprouting and abnormal neuronal excitability [6].

Among the interleukin- 1 superfamily, IL- $1 \alpha$ and IL-1 $\beta$ possess strongly proinflammatory effects. They have a natural antagonist, IL-1 receptor antagonist (IL-1Ra). IL-1Ra regulates IL- $1 \alpha$ and IL-1 $\beta$ proinflammatory activity by competing with them for binding sites of the receptor [8]. IL-1 $\beta$ has been shown to reduce GABA-mediated inhibition [9] and to facilitate NMDA-receptor mediated calcium influx [10]. Studies have also shown that intrahippocampal injection of IL-1 $\beta$ can prolong the duration of kainic acid induced seizures in adult animals [11].

Glatiramer acetate (GA), comprised of four amino acids, L-glutamic acid, L-alanine, L-lysine and L-tyrosine [12], approved by the FDA for the treatment of relapsing remitting multiple sclerosis (RRMS), is the first drug ever to show clear therapeutic efficacy in multiple sclerosis. It is also the first therapeutic agent to have a copolymer as its active ingredient [13]. GA has anti-inflammatory effects as well as being neuroprotective within the CNS, and has pleiotropic effects on the immune system [14]. In addition to multiple sclerosis, GA has been shown to be of benefit in different experimental diseases models such as amyotrophic lateral sclerosis [15] and Alzheimer's disease [16].

Although most of the mechanism(s) underlying GA-induced neuroprotection have been attributed to T cells, some evidence suggests GA has T-cell independent effects on targets including antigen-presenting cells, B cells and the IL-1 system $[17,18]$. Studies have shown that GA increases the blood level of IL-1Ra [19], both in RRMS patients and in experimental autoimmune encephalomyelitis mice. However, how GA affects these inflammatory cytokines and how IL-1 $\alpha$ and IL-1 $\beta$, correlate with seizure activities remains mostly unknown.

Molecular studies of epileptogenesis and epilepsy have demonstrated that specific ion channels are important players in both genetic and acquired forms of epilepsy [2022], especially the voltage-gated sodium channels [23]. The ionic mechanism underlying bursting neuronal behavior are not fully clarified, but sodium channels have been found to be significantly involved $[22,24]$. Different types of sodium channels expressed in both glutamatergic and GABAergic cell types might play unequal roles in excitability, enhancing of synaptic potentials, generation of subthreshold oscillations, facilitation of repetitive firing, and prolongation of depolarized potentials $[23,25]$.

Given the current understanding of neuroinflammation in animal models of epilepsy and GA's clinical potential and pharmacological properties, the aim of this study was the potential of GA for the treatment of both acute and chronic epileptic seizures as well as epileptogenesis. Added to this was the characterization of the neuroprotective spectrum of 


\section{Cellular Physiology Cell Physiol Biochem 2018;50:150-168 \begin{tabular}{ll|l} 
DOI: 10.1159/000493965 & C 2018 The Author(s). Published by S. Karger AG, Basel \\
www.karger.com/cpb
\end{tabular}}

Lai et al.: Effect of Glatiramer Acetate on Epileptogenesis and Seizures

GA, and a correlation of the level of IL- $1 \alpha$ and IL-1 $\beta$ with the neuroprotective effects of GA and an exploration of the potential ionic mechanisms.

\section{Materials and Methods}

\section{Ethics Statement}

All experiments were done in accordance with the guidelines of the Experimental Ethics Committee of the National Cheng Kung University. Procedures for animal experimentation were reviewed and approved by the Institutional Animal Care and Use committee.

\section{Animals}

Adult Sprague-Dawley male rats weighing 200-300 gm were purchased from National Cheng Kung University and housed in the University Animal Center. They had free access to water and rodent diet pellets (Richmond Standard; PMI Feeds, Inc, St Louis, MO) and efforts were made to reduce the number of animals used.

\section{Grouping}

On day 1, blood samples were taken from all the rats to determine the levels of IL-1 $\alpha$ and IL-1 $\beta$ and provide a baseline. The rats were then divided into two groups: the control group received intraperitoneal (ip) injections of normal saline; and the GA group received intraperitoneal (ip) injections of $150 \mu \mathrm{g} / \mathrm{kg}$ of GA (Fig. 1). The two groups were then injected with lithium chloride (3 meq $/ \mathrm{kg}$, ip) (Sigma-Aldrich Co, St Louis, MO) 18-20 hours before a subcutaneous (sc) pilocarpine injection (60 mg/kg) (Sigma- Aldrich) to induce status epilepticus. To reduce the peripheral consequences of the pilocarpine, the rats were injected (sc) with methylscopolamine (25 mg/kg) (Sigma-Aldrich) 30 minutes before the pilocarpine administration [26-28]. Both groups of rats were blood-sampled for IL- $1 \alpha$ and IL-1 $\beta$ at stage 4-5 seizure. The brains were removed from some rats for the evaluation of acute neuronal damage. To evaluate the effect of GA on chronic seizures and excitotoxicity, GA was administered to the GA group (150 $\mathrm{gg} / \mathrm{kg} / \mathrm{day}$, ip) and $0.9 \%$ normal saline $(0.001 \mathrm{ml} / \mathrm{g})$ to the control group, for 7 consecutive days, starting 24 hours after status epilepticus. Monitoring for spontaneous recurring seizures, using video cameras mounted above the cages, was started 7 days after status epilepticus and carried out for 8 hours per day, over 5 consecutive days [29]. A trained technician, blinded to the experimental design, examined the videos for seizure behavior (ie, running, jumping, rearing, lordosis, and erect tail). When seizure-like activity was observed, the video was reviewed to confirm seizure behavior. Following this, third blood samples for IL- $1 \alpha$ and IL-1 $\beta$ were taken. Chronic network hyperexcitability was evaluated using Timm's staining.

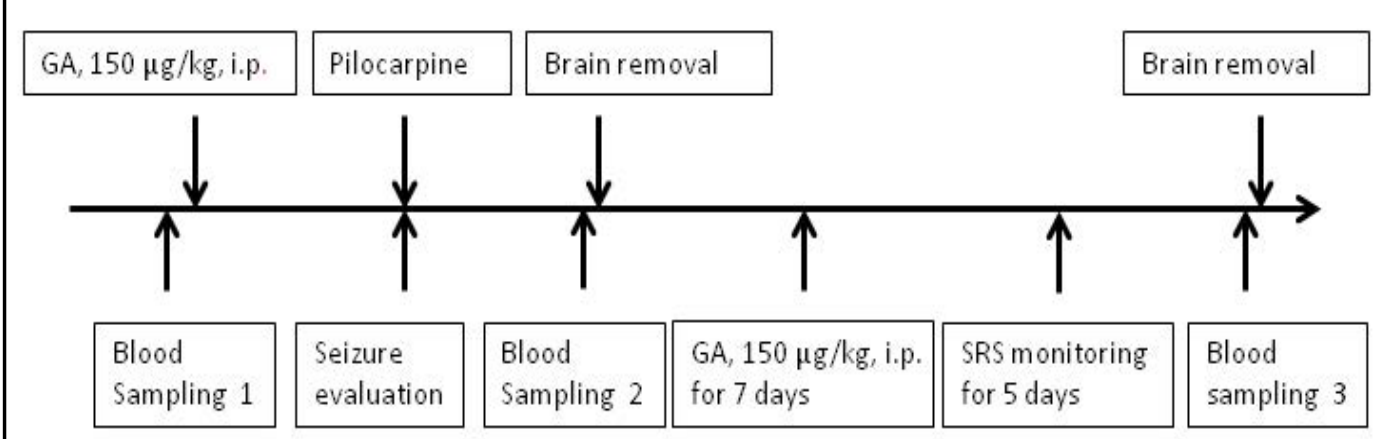

Fig. 1. Experimental protocol. 


\section{Cellular Physiology Cell Physiol Biochem 2018;50:150-168 \begin{tabular}{l|l} 
and Biochemistry Published onine: 3 October 2018 & $\begin{array}{l}\text { C } 2018 \text { The Author(s). Published by S. Karger AG, Basel } \\
\text { www.karger.com/cpb }\end{array}$
\end{tabular}

Lai et al.: Effect of Glatiramer Acetate on Epileptogenesis and Seizures

\section{Enzyme-linked immunosorbent assay}

The quantitative sandwich enzyme immunoassay technique was used for the determination of the blood level of IL- $1 \alpha$ and IL-1 $\beta$. The microplates used were precoated with a monoclonal antibody specific for IL- $1 \alpha$ and IL-1 $\beta$. Standards and samples were pipetted into the wells and any IL-1 $\alpha$ and IL-1 $\beta$ present was bound by the immobilized antibody. After washing, an enzyme-linked polyclonal antibody specific for IL- $1 \alpha$ and IL-1 $\beta$ was added to the wells. After washing, a substrate solution was added and color was developed in proportion to the amount of IL- $1 \alpha$ and IL- $1 \beta$ bound in the initial step.

\section{Lithium-pilocarpine seizure modeling}

The behavioral characteristics of the rats during seizures were similar to those in earlier studies [26, $27,30,31]$. Within 5 minutes of the pilocarpine injection, the rats developed piloerection and other signs of cholinergic stimulation. Over the following 15 to 20 minutes, mouth and facial movements were exhibited, as well as head bobbing and nodding, scratching, masticatory automatism, and exploratory behavior (stages 1-2). Episodes of head and bilateral forelimb myoclonic movements (stage 3) started at around 20 to 25 minutes and progressed to status epilepticus (stages 4-5) with rearing and falling at about 50 minutes after the pilocarpine injection. For classification of the seizure as "severe", we used the criteria as stage 3 and above seizures in Racine seizure classification [26-28, 30, 32].

SE was characterized by sustained clonic seizure activity accompanied by episodes of rearing and falling. Seizure parameters, including latency to the first seizure, and the duration of the severe seizures which occurred were recorded and evaluated. The rats were monitored for 24 hours following status epilepticus, and supportive care was implemented, including body temperature maintenance, feeding, and adequate hydration. Status epilepticus-related mortality was calculated during the first 24 hours after seizures.

\section{Histopathology}

Cresyl violet staining. The rats in both groups were anesthetized with pentothal $(60 \mathrm{mg} / \mathrm{kg}$, ip) 24 hours after status epilepticus and the brains were removed and stored at $-80^{\circ} \mathrm{C}$. Coronal sections $(20 \mu \mathrm{m}$ thick) of the entire hippocampus were fixed in formaldehyde for cresyl violet staining, as previously described [33]. The stained sections were examined for gross indications of damage to the hippocampus.

The cells were counted in Nissl-stained sections (10 $\mu \mathrm{m}$ thick) and the severity of neuronal damage in different subfields of the hippocampus were scored semi- quantitatively as follows: score $0=$ no damage; $1=$ less than 10\%; 2 = between 11 and 50\% neuronal loss; and $3=$ greater than or equal to $50 \%$ neuronal loss $[26,34]$. Counts were done at $\times 400$ using a computerized image analysis system (Image Plus 2.0; Motic, Richmond, Canada), and the hippocampal subfields were defined by an imaginary line connecting the tips of the granule cell layer blades, which separated the cornu ammonis (CA)3c (medially) from CA3b (laterally), and CA2 from CA1 [33]. The delineated counting area was $200 \mu \mathrm{m} \times 150 \mu \mathrm{m}$ situated over the region of interest. Values from different groups were obtained blindly and averaged in each group.

Timm staining. The rats were deeply anesthetized with pentobarbital and then transcardially perfused with $0.58 \%$ sodium sulfide followed by $4 \%$ paraformaldehyde. The brains were post-fixed in paraformaldehyde for 24 hours and then placed in a 30\% sucrose solution until they sank to the bottom of the vessel. Coronal sections ( $20 \mu \mathrm{m}$ thick) through the entire hippocampus were cut on a freezing microtome. Every sixth section was stained with Timm's stain [35]. In brief, the sections were developed in the dark for 10 to 45 minutes in a $200-\mathrm{ml}$ solution containing $5.1 \mathrm{gm}$ of citric acid, $4.7 \mathrm{gm}$ of sodium citrate, $3.47 \mathrm{gm}$ of hydroquinone, $212.25 \mathrm{mg}$ of $\mathrm{AgNO}_{3}$, and $120 \mathrm{ml}$ of $50 \%$ gum Arabic. The staining was assessed from the septal area to the temporal hippocampus (the region between 2.8 and $3.8 \mathrm{~mm}$ posterior to the bregma). A semi-quantitative scale was used to evaluate the degree of axonal sprouting in the prefrontal cortex [33]. The score criteria were 0: no granules; 1 : occasional discrete granule bundles; 2: occasional-to-moderate granules; 3: prominent granules; 4: a prominent near continuous granule band; and 5: a continuous or nearly continuous dense granule band.

\section{Immunohistochemistry for TNF- $\alpha$}

This was performed 14 days after status epilepticus. Rats were anesthesized and perfused with phosphate-buffered saline (PBS, PH 7.4) containing 4\% paraformaldehyde. After post-fixing in $4 \%$ paraformaldehyde overnight, the brains were dehydrated by $30 \%(\mathrm{w} / \mathrm{v})$ sucrose in $\mathrm{PBS}$ at $4^{\circ} \mathrm{C}$ for 2 days, and 


\section{Cellular Physiology Cell Physiol Biochem 2018;50:150-168 and Biochemistry Published 10.1159/000493965 $2018 \begin{aligned} & \text { D } 2018 \text { The Author(s). Published by S. Karger AG, Basel } \\ & \text { www.karger.com/cpb }\end{aligned}$

Lai et al.: Effect of Glatiramer Acetate on Epileptogenesis and Seizures

then sectioned coronally (20 microm thickness) in the hippocampus. Slides were infused with $0.3 \% \mathrm{H} 2 \mathrm{O} 2$ in methanol for 30 minutes to inhibit the endogeneous peroxidase activity, and followed by incubation with blocking solutions contained $2 \%$ normal goat serum and $0.3 \%$ triton. The sections were incubated in PBS containing the specific anti-TNF $-\alpha$ antibody $(1: 200, \mathrm{Abcam})$ at $4^{\circ} \mathrm{C}$ overnight. After washing with PBS, the sections were incubated with the secondary antibody, biotin-labeled anti-rabbit IgG antibody in PBS for one hour. The sections were further incubated with a mixture of avidin and horseradish peroxidase-conjugated biotin for one hour, and visualized by using diaminobenzidine as a substrate. Sections were examined by light microscope (Nikon E400) and the image captured with a video camera coupled to a desktop computer. The quantitative analysis of TNF- $\alpha$ expression was performed. The intergrated optical density (IOD) of TNF- $\alpha$ signals were analyzed at x400 microscopic magnification per visual field (one visual field $=0.096$ $\mathrm{mm} 2$ ) by ImagePro Plus 6.0 software. The visual fields within a cross-sectional area in the hippocampus were analyzed and averaged.

\section{NG108-15 cell line preparation and differentiation}

The NG108-15 cell line is widely used as a neuron model in electrophysiology and pharmacology studies [36-38]. This cell line has been reported to express Kv3.1 mRNAs and to exhibit the activity of delayed rectifier $\mathrm{K}^{+}\left(\mathrm{K}_{\mathrm{DR}}\right)$ channels and there will be an increase in the expression levels of $\mathrm{Na}_{\mathrm{v}} 1.7$ in NG10815 cells when neuronal differentiation is induced by pretreatment with a cyclic AMP analog [39].

The clonal strain NG108-15 cell line, formed by Sendai virus-induced fusion of the mouse neuroblastoma clone N18TG-2 and the rat glioma clone Cg BV-1, was originally obtained from the European Collection of Cell Cultures (ECACC-88112302; Wiltshire, UK). NG108-15 cells were kept as monolayer cultures at a density of $10^{6} / \mathrm{ml}$ in plastic dishes containing Dulbecco's modified Eagle's medium (Life Technologies; Grand Island, NY, USA) supplemented with $100 \mu \mathrm{M}$ hypoxanthine, $1 \mu \mathrm{M}$ aminopterin, $16 \mu \mathrm{M}$ thymidine, and $5 \%$ fetal bovine serum, in a humidified incubator equilibrated with $90 \%$ air $/ 10 \% \mathrm{CO}_{2}$ at $37^{\circ} \mathrm{C}$. The experiments were generally performed after 5 days of subculture (60-80\%).

To induce neuronal differentiation, the culture medium was replaced with one containing $1 \mathrm{mM}$ dibutyryl cyclic-AMP after which cells were incubated at $37^{\circ} \mathrm{C}$ for $1-7$ days. NG108-15 cells proliferated well in this medium, but would stop proliferation and show the growth of neurites in response to dibutyryl cyclic-AMP [39]. The numbers of neurites and varicosities were found to be significantly increased in NG10815 cells treated with $1 \mathrm{mM}$ dibutyryl cyclic AMP. After differentiation, $\mathrm{Na}_{\mathrm{v}} 1.7$, as a voltage-gated sodium channel with a critical role in the generation and conduction of action potentials, showed significantly higher expression levels [39].

\section{Patch clamp technology: Electrophysiological measurements}

Cells were dissociated and an aliquot of cell suspension was transferred to a recording chamber mounted on the stage of an inverted DM-IL microscope (Leica Microsystems, Wetzlar, Germany) for the experiments. NG108-15 neurons were bathed at room temperature $\left(20-25^{\circ} \mathrm{C}\right)$ in normal Tyrode's solution containing $1.8 \mathrm{mM} \mathrm{CaCl}_{2}$. Patch pipettes were pulled from Kimax-51 glass capillaries (Kimble; Vineland, NJ) on a PP-830 puller (Narishige, Tokyo, Japan) and fire-polished on an MF-83 microforge (Narishige). The resistances of the pipettes when filled with the internal solution were between 3 and $5 \mathrm{M} \Omega$. Ion currents were measured with glass pipettes in whole-cell configuration of the patch-clamp technique using an RK400 (Biologic, Claix, France) or an Axopatch 200B patch-clamp amplifier (Molecular Devices, Sunnyvale, CA) $[38,40]$. All potentials were corrected for liquid junction potential.

The concentration-response data for inhibition of $I_{\mathrm{Na}}$ seen in differentiated NG108-15 cells were fitted to the Hill equation:

$$
\text { Percentage inhibition }=\frac{E_{\max } \times[C]^{n_{H}}}{[C]^{n_{H}}+I C_{50}^{n_{H}}},
$$

where $[\mathrm{C}]$ is the GA concentration, $\mathrm{IC}_{50}$ and $n_{\mathrm{H}}$ are the concentration required for a $50 \%$ inhibition and the Hill coefficient, respectively, and $E_{\max }$ is the maximal inhibition of $I_{\mathrm{Na}}$ induced by GA.

\section{Statistical analyses}

Data from seizure testing, behavioural and pathological score: continuous variables were assessed using the t-test, or ANOVA, followed by Fisher's Least Significant Difference tests. When data are not 
Lai et al.: Effect of Glatiramer Acetate on Epileptogenesis and Seizures

normally distributed, analyses were performed using the nonparametric ANOVA Kruskal-Wallis $\mathrm{H}$ test followed by Dunn's multiple comparison tests for non-repeated measures and Friedman tests for repeated measures. ANOVA was used where sessions or quadrants were treated as a within-subject factor and groups as a between-subject factor. Analyses were done using Chi-square and Yates Chi-square tests and/or Fisher exact probability for nominal variables.

\section{Results}

GA delayed the onset of seizures, attenuated severe seizures, and also reduced status epilepticus-related mortality.

Although acute administration of GA did not significantly prolong the latency to first seizures (control: $350 \pm 50 \mathrm{sec}$ versus GA: $550 \pm 60 \mathrm{sec}$ ) (Fig. $2 \mathrm{~A}$ ), it delayed the onset of severe seizures and attenuated them. Fig. 2B shows that the latency to severe seizures was significantly longer in the GA group than in the control group (stage 3 and above; control: $669.8 \pm 64 \mathrm{sec}$ versus GA: $1172.5 \pm 115 \mathrm{sec}$; unpaired t-test, $p<0.01$ ). Furthermore, the duration of severe seizures in the GA group was much shorter (control: $385 \pm 90$ sec versus GA: $49 \pm 8$ sec; $p<0.01$ ) (Fig. 2C). Status epilepticus-related mortality was also much lower in the GA group which had far fewer deaths than the control group (control 9/16 versus GA 2/16, Chi Square test with Fisher exact probability, $p<0.01$ ) (Fig. 2 D).

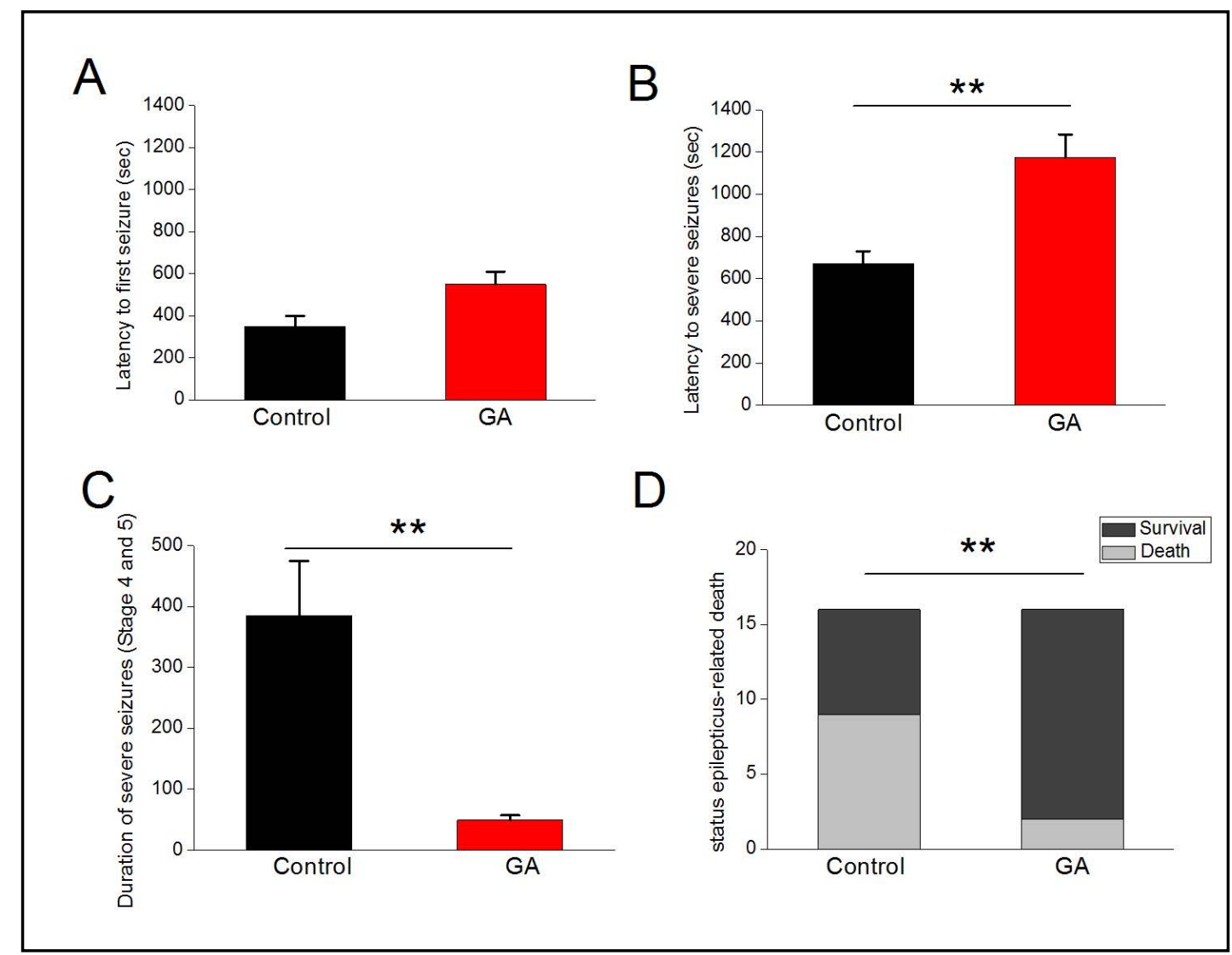

Fig. 2. GA delayed onset and attenuated severe seizures as well as reducing status epilepticus-related mortality. (A) Acute administration of GA did not significantly prolong the latency to first seizures, but delayed the onset of severe seizures and attenuated them ( $B$ and $C$, both $p<0.01$ ). (D) The GA group showed a much lower death rate in status epilepticus-related mortality $(n=16$ in each group, $p<0.01)$. 
GA attenuated post-status epilepticus acute neuronal damage

Twenty-four hours after status epilepticus, cresyl violet staining showed that the control group had significant neuron loss in the hippocampal CA3 but not CA1, compared with the GA group (Fig. 3). The difference in cell counts in the CA3 area between the two groups was significant $(p<0.05$, Fig. $3 \mathrm{~A})$. A blind semi-quantitative analysis also showed that the control group had significant hippocampal neuron damage compared with the GA group in CA3 (Control: $2.5 \pm 0.4$ vs GA: $2.2 \pm 0.4, p<0.05$, Fig. $3 A$ ). However, there was no significant difference between the control and the GA group in CA1 (Control: $1.9 \pm 0.5$ vs GA: $1.9 \pm 0.5$, $p>0.1$ ) (Fig. 3B).

\section{GA attenuated spontaneous recurring seizures and chronic excitotoxicity}

The rate of spontaneous recurring seizures, was significantly lower in the GA group compared to the control group (Fig. 4A). The average seizure count was $7 \pm 4$ in the control group and $3 \pm 2$ in the GA group $(p<0.05)$. Chronic excitotoxicity in the control group, as evaluated by Timm's staining, showed significantly more mossy fiber sprouting and a higher Timm's score than the GA group in the CA3 (Control: $4 \pm 0.4$ vs GA: $3.2 \pm 0.3, p<0.05$ ) (Fig. 4B). There was no significant difference between the control and the GA group in CA1 (Control: $3.6 \pm 0.3$ vs GA: $3.5 \pm 0.3, p>0.1$ ) (Fig. 4 C).

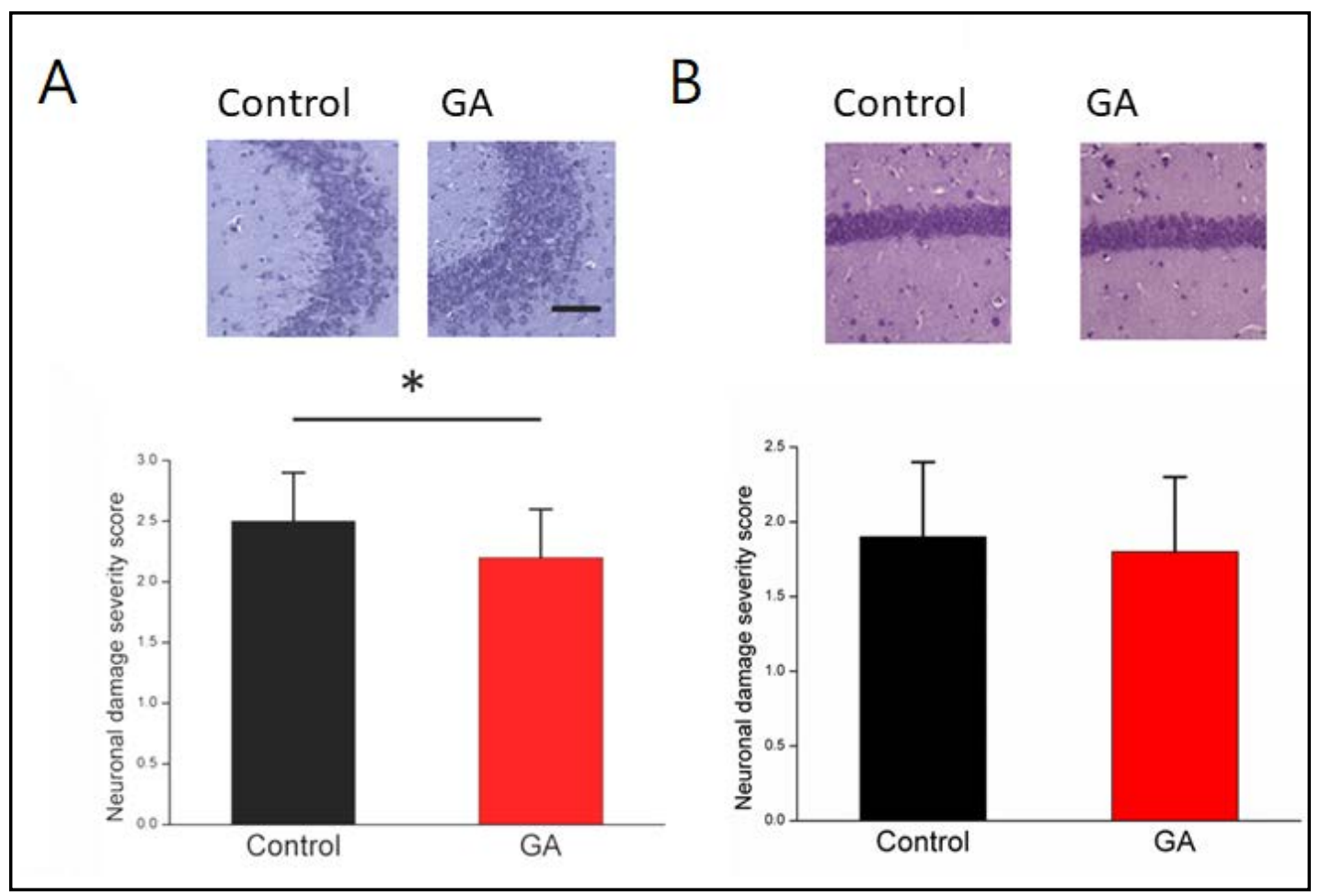

Fig. 3. GA attenuated post-status epilepticus acute neuronal damage in hippocampal CA3 region. Photomicrographs of cresyl-stained coronal sections of the hippocampal CA3 from the control and GA groups (A). Hippocampal CA3 neuronal loss was more severe than in the control group. A blind semi-quantitative analysis of neuronal damage showed a significant difference between the two groups $(n=7$ in each group, $\mathrm{p}<0.05)$. Photomicrographs of cresyl-stained coronal sections of the hippocampal CA1 from the control and GA groups (B). Hippocampal CA1 neuronal loss was similar in the control and the GA group. A blind semiquantitative analysis of neuronal damage did not show a significant difference between the two groups $(n=7$ in each group, $\mathrm{p}<0.05)$. The scale bar represents $100 \mu \mathrm{M}$. 
Fig. 4. GA attenuated spontaneous recurring seizures and chronic excitotoxicity in CA3. GA significantly reduced spontaneous recurring seizures compared to the control group (A). The average seizure count was $7 \pm 4$ in the control group and $3 \pm 2$ in the GA group $(n=7$ in each group, $\mathrm{p}<0.05$ ). The Timm's score was used to measure and evaluate excitotoxicity (B and C). The scale bar represents 100 $\mu \mathrm{M}$. The control group showed significantly more mossy fiber sprouting and a higher Timm's score than the GA group in the CA3 (B) but not CA1 region (C) $(\mathrm{p}<0.05)$.

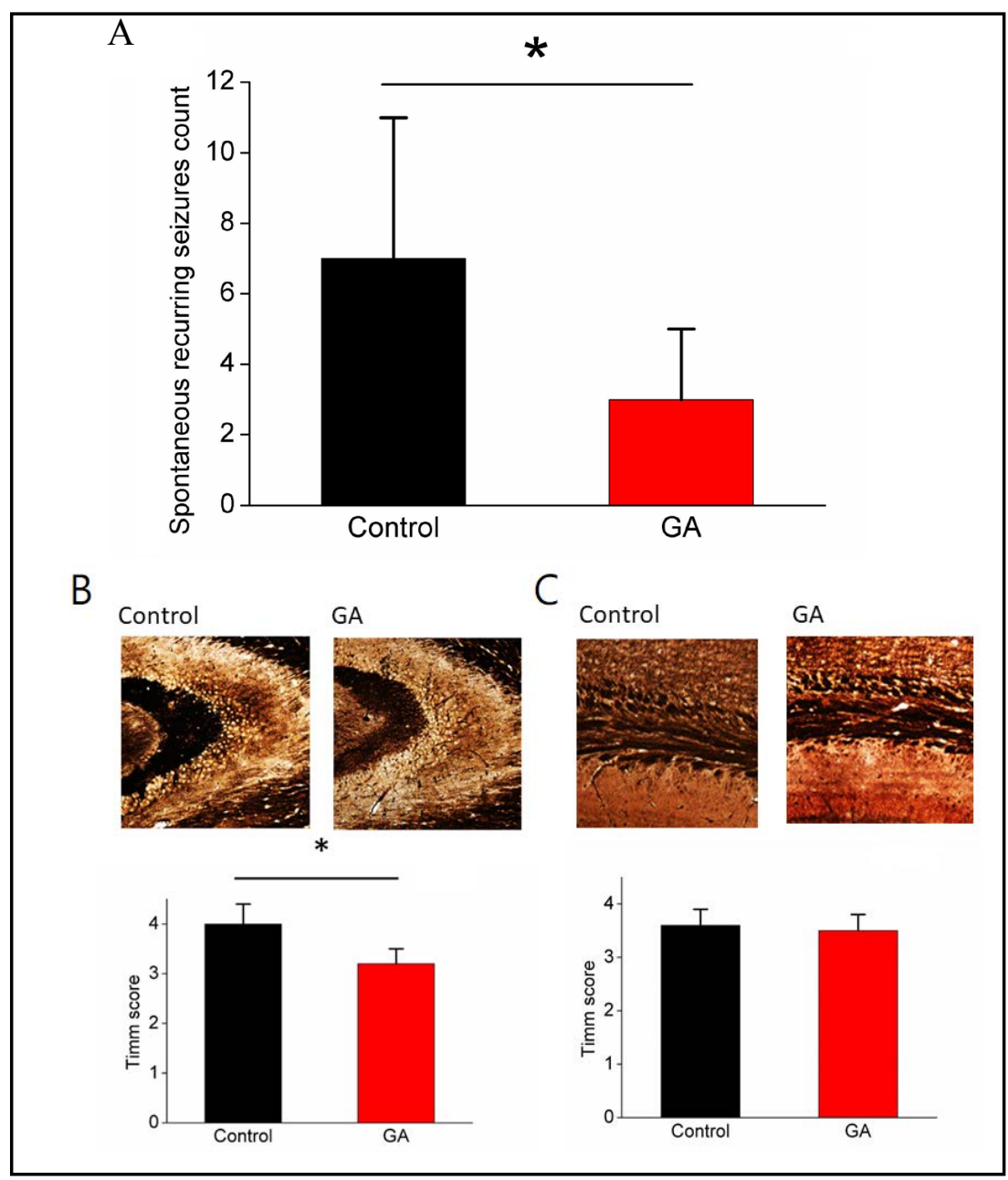

The effect of $G A$ on $I L-1 \alpha$ and $I L-1 \beta$

There were similar levels of IL- $1 \alpha$ in both the control and GA group at the baseline and the post-status epilepticus acute stage (Control-1 vs GA-1: $430 \pm 125.3$ vs $328.2 \pm 38.2, p>$ 0.1 ; Control-2 vs GA-2: $473.1 \pm 49.3$ vs $475.6 \pm 94.6, p>0.1$ ). However, the IL- $1 \alpha$ level in the GA group was significantly lower than that in the control group, at the post-status epilepticus chronic stage (Control-3 vs GA-3: $1456.3 \pm 101.3$ vs $569.4 \pm 82.8, p<0.01$ ) (Fig. 5 A). Notably, the IL-1 $\beta$ level was similar between the GA and the control group at the baseline, post-status epilepticus acute and chronic stages (Control-1 vs GA-1: $1275.7 \pm 172.5$ vs $1324.8 \pm 334.3$; Control-2 vs GA-2: $1169.8 \pm 157.5$ vs $1229.6 \pm 208.5$; Control-3 vs GA-3: $1560.2 \pm 343.6$ vs $1589.0 \pm 150.5$, all $p>0.1$ ) (Fig. 5B).

The lack of effect of GA on TNF- $\alpha$ at the post-status epilepticus chronic stage

To further characterize the role of inflammation in the epileptogenesis, TNF- $\alpha$ level, specifically in the hippocampous at the post-status epilepticus stage was investigated. We found similar TNF- $\alpha$ level (IOD ratio) in the GA and the control groups (at CA1, control vs GA: $169934.8 \pm 11913.1$ vs $168539 \pm 10021.2, p>0.1$; at CA3, $169697.4 \pm 67671.5$ vs $145339 \pm$ $31740.3, p>0.1$; at dentate gyrus: $139873.1 \pm 32946.4$ vs $121069 \pm 13242.7, p>0.1$ ) (Fig. 5 C). 
Effect of GA on voltagegated $\mathrm{Na}^{+}$current $\left(\mathrm{I}_{\mathrm{Na}}\right)$ in differentiated NG108-15 neurons

To characterize the ionic effect of GA, its effect on $I_{\mathrm{Na}}$ in differentiated NG10815 neurons in response to depolarizing pulses was investigated. As can be seen in Fig. 6A, there was a significant reduction in the $I_{\text {Na }}$ peak, which was reduced from $1453 \pm 103$ to $1133 \pm$ $98 \mathrm{pA}(\mathrm{n}=9)$, in the presence of GA at a concentration of $10 \mathrm{nM}$. After washout of the GA, current amplitude was partially returned to the control level. Moreover, when cells were held at -80 $\mathrm{mV}$ and depolarizing pulses of $-20 \mathrm{mV}$ with a duration of 60 msec were applied, GA (10 $\mathrm{nM}$ ) produced no significant change in the kinetics of activation or inactivation of $I_{\mathrm{Na}}$ in these neurons (control: $\tau_{\text {act }}=2.3 \pm 0.1 \mathrm{msec}, \tau_{\text {inact(f) }}=4.1$ $\pm 0.3 \mathrm{msec}, \tau_{\text {inact(s) }}=18.2 \pm 0.7$ $\operatorname{msec}[\mathrm{n}=7] ; \mathrm{GA}: \tau_{\text {act }}=2.3 \pm 0.1$ $\mathrm{msec}, \tau_{\text {inact }(\mathrm{f})}=4.2 \pm 0.2 \mathrm{msec}$, $\left.\tau_{\text {inact(s) }}=18.3 \pm 0.6 \mathrm{msec}[\mathrm{n}=7]\right)$ (Fig. 6A and B). The overall I-V relationship of peak $I_{\mathrm{Na}}$ also remained unaltered in the presence of GA (Fig. 6C).

These experiments allowed a relationship between the GAconcentration and the percentage inhibition of $I_{\mathrm{Na}}$ to be determined. Each cell was depolarized from -80 to $-20 \mathrm{mV}$ with a duration of $60 \mathrm{msec}$ and the peak amplitude of $I_{\mathrm{Na}}$ was measured in the presence of different concentrations of GA. As shown in Fig. 7, GA (1-300 nM) suppressed the peak amplitude of $I_{\mathrm{Na}}$ in a concentration-dependent manner. The $\mathrm{IC}_{50}$ value for GA-induced inhibition of $I_{\mathrm{Na}}$

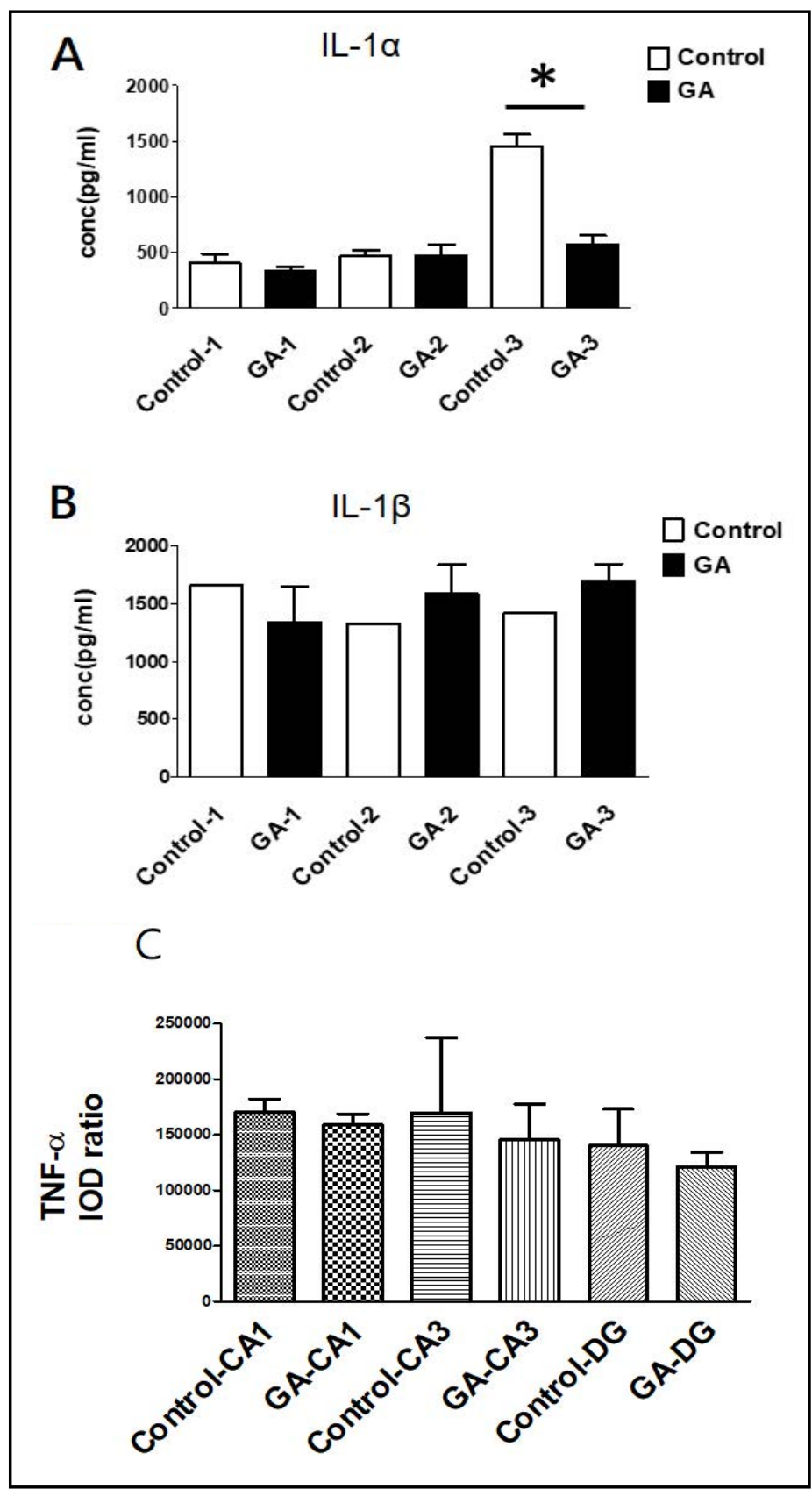

Fig. 5. The effect of GA on systemic IL- $1 \alpha$ and IL-1 $\beta$ and hippocampal TNF- $\alpha$. There were similar levels of IL- $1 \alpha$ in both the control and GA groups at the baseline (Control-1 and GA-1) and at the post-status epilepticus acute stage (Control-2 and GA-2). However, the IL-1 $\alpha$ level at the GA group was significantly lower than that of the control group, at the post-status epilepticus chronic stage (Control-3 and GA-3) $(\mathrm{p}<0.01)$ (Fig. 5A). Similar IL-1 $\beta$ levels in both the GA and the control group were seen at the baseline, post-status epilepticus acute and chronic stages (all $p>0.1$ ) (Fig. 5B). TNF- $\alpha$ level, specifically in the hippocampous at the post-status epilepticus chronic stage was similar in both the GA and the control group (at the CA1, CA3 and dentate gyrus) (Fig. 5. C). 


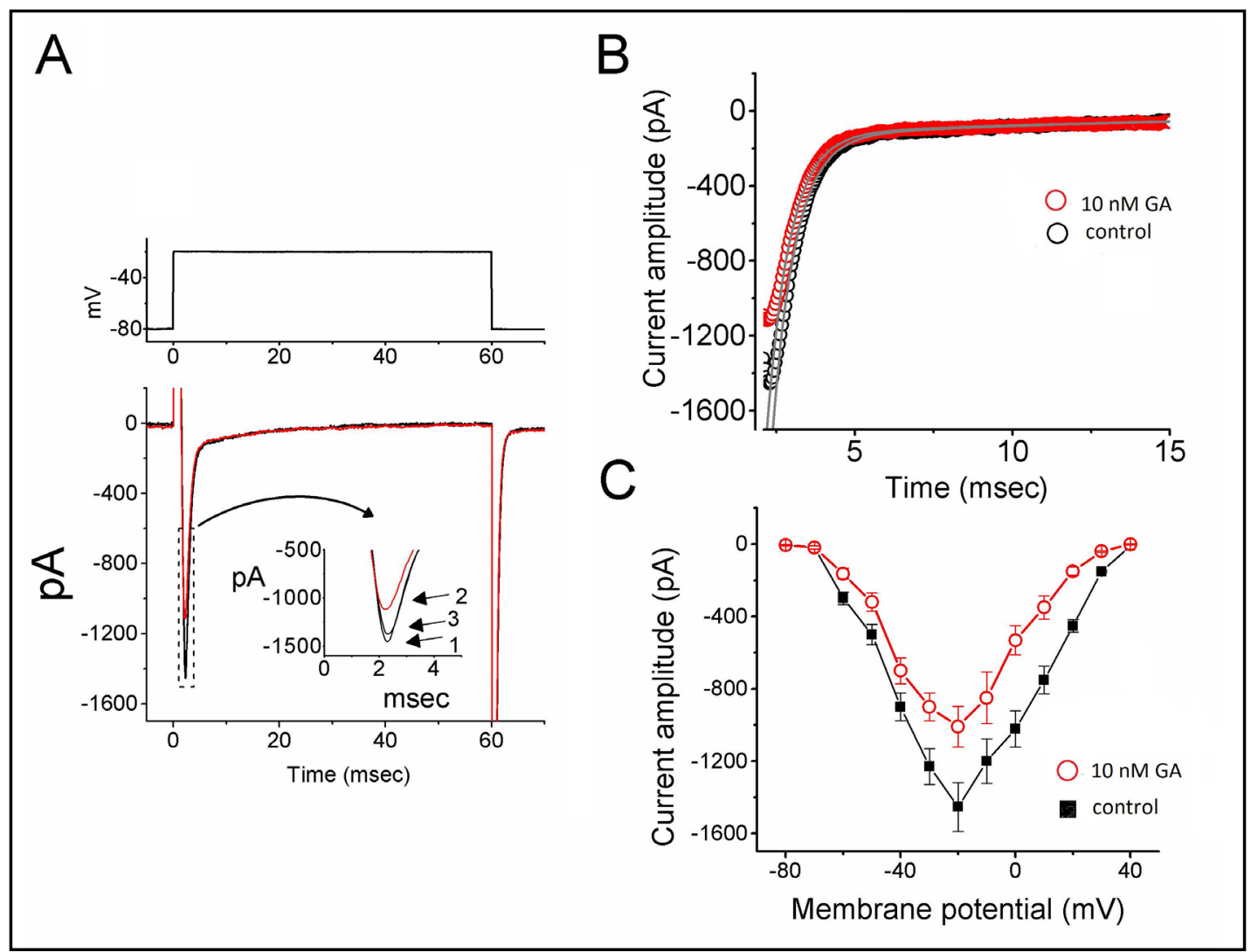

Fig. 6. The inhibitory effect of GA on voltage-gated $\mathrm{Na}^{+}$current $\left(\mathrm{I}_{\mathrm{Na}}\right)$ in NG108-15 cells differentiated with 1 $\mathrm{mM}$ dibutyryl cyclic AMP. In these experiments, cells were bathed in $\mathrm{Ca}^{2+}$-free Tyrode's solution containing $0.5 \mathrm{mM} \mathrm{CdCl}$ and $10 \mathrm{mM}$ tetraethylammonium chloride. The pipettes were filled with a $\mathrm{Cs}^{+}$-containing solution. (A) Original currents obtained in control (1), during exposure to $10 \mathrm{nM} \mathrm{GA} \mathrm{(2)} \mathrm{and} \mathrm{after} \mathrm{washout}$ of GA (3). The upper part in (A) indicates the voltage protocol used. Inset shows the expanded traces from the dashed box. (B) Time course of $\mathrm{I}_{\mathrm{Na}}$ inactivation obtained in control (black) and during exposure to 10 nM GA (red). Notably, the time courses of $\mathrm{I}_{\mathrm{Na}}$ inactivation in response to depolarizing pulses were fitted by a double exponential and showed no differences in the absence or presence of $10 \mathrm{nM} \mathrm{GA}$. (C) Averaged I-V relationships of $\mathrm{I}_{\mathrm{Na}}$ obtained in control ( $\square$ ) and presence of $10 \mathrm{nM}$ GA (O). Each point represents the mean \pm SEM ( $n=6-12)$.

Fig. 7. Concentration-response relationship for GA-induced inhibition of $\mathrm{I}_{\mathrm{Na}}$ in differentiated NG108-15 cells. Cells were bathed in $\mathrm{Ca}^{2+}$-free Tyrode's solution containing $0.5 \quad \mathrm{mM \quad CsCl}{ }_{2}$ and $10 \mathrm{mM}$ tetraethylammonium chloride. Pipette was filled with $\mathrm{Cs}^{+}$-containing solution. Each point represents the mean \pm SEM $(n=6$ 8). The smooth line represents the best fit to the Hill equation as described in Materials and Methods. The $\mathrm{IC}_{50}$ value and Hill coefficient were $13 \mathrm{nM}$ and 1.2, respectively.

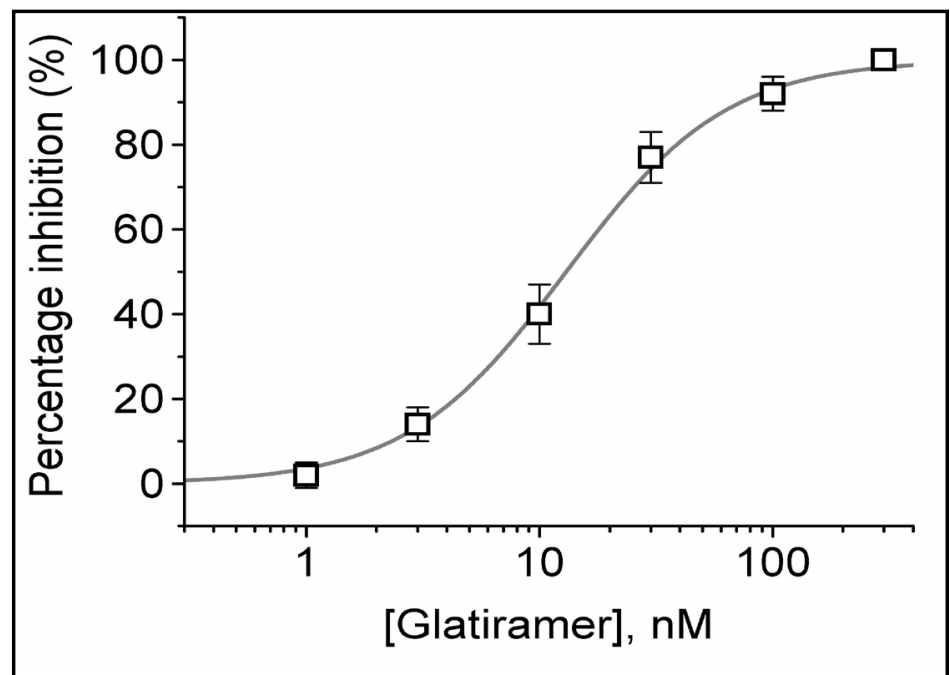


Lai et al.: Effect of Glatiramer Acetate on Epileptogenesis and Seizures

was calculated to be $13 \mathrm{nM}$. GA at a concentration of $300 \mathrm{nM}$ almost completely suppressed the peak amplitude of $I_{\mathrm{Na}}$. These results clearly showed that GA had a significant depressant action on the $I_{\mathrm{Na}}$ functionally expressed in differentiated NG108-15 cells.

\section{Effect of GA on steady-state inactivation of $I_{N a}$}

To characterize the stimulatory effects of GA on $I_{\mathrm{Na}^{\prime}}$ the voltage-dependence of GA on $I_{\mathrm{Na}}$ was investigated. Fig. 8 shows the steady-state inactivation curve of $I_{\mathrm{Na}}$ in the absence and presence of GA ( $10 \mathrm{nM})$. A two-step voltage pulse protocol was applied. In these experiments, a 20 msec conditioning pulse to various membrane potentials preceded the test pulse (50 msec duration) to $-20 \mathrm{mV}$ from a holding potential of $-80 \mathrm{mV}$. The interval between the two sets of voltage pulses was $30 \mathrm{sec}$ to allow complete recovery of $I_{\mathrm{Na}}$. The relationship between the membrane potential and the normalized amplitude of $I_{\mathrm{Na}}$ with or without the presence of GA (10 nM) were plotted and fitted to a Boltzmann function using nonlinear regression analysis:

$$
I=\frac{I_{\max }}{1+\exp \left(\frac{V-a}{b}\right)},
$$

where $I_{\max }$ represents the maximal activated $I_{\mathrm{Na}^{\prime}} V$ is the membrane potential in $\mathrm{mV}$, $a$ is the membrane potential for half-maximal inactivation, and $b$ is the slope factor of the inactivation curve. In the control, $a=-49.5 \pm 1.2 \mathrm{mV}, b=7.0 \pm 0.4 \mathrm{mV}(\mathrm{n}=6)$, whereas in the presence of GA $(10 \mathrm{nM}), a=-60.1 \pm 1.2 \mathrm{mV}, b=6.9 \pm 0.3 \mathrm{mV}(\mathrm{n}=6)$. It is clear from these results that GA not only decreased the maximal conductance of $I_{\mathrm{Na}}$, but also shifted the inactivation curve of this current to a hyperpolarized potential by approximately $10 \mathrm{mV}$. However, no significant change in the slope (ie $b$ value) of the inactivation curve during cell exposure to GA was found.

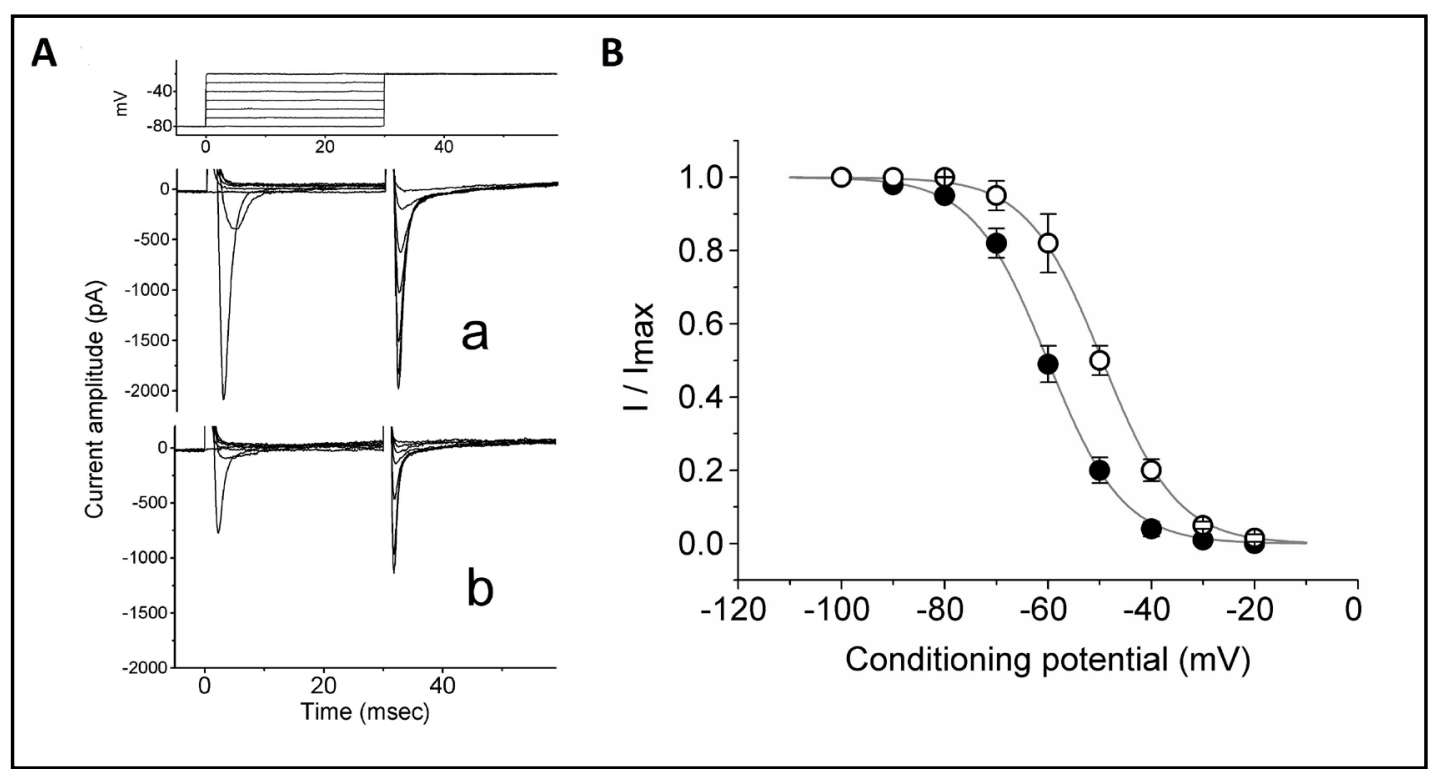

Fig. 8. The effect of GA on the inactivation curve of $\mathrm{I}_{\mathrm{Na}}$ in differentiated NG108-15 cells. Conditioning voltage pulses, with a duration of $30 \mathrm{msec}$ were applied from a holding potential of $-80 \mathrm{mV}$. After each conditioning pulse, a test pulse to $-20 \mathrm{mV}$ with a duration of $30 \mathrm{msec}$ was applied to evoke $\mathrm{I}_{\mathrm{Na}}$. (A) Original current traces obtained in the absence (a) and presence (b) of $10 \mathrm{nM} \mathrm{GA}$. The uppermost part in (A) shows the induced voltage protocol used. (B) Steady-state inactivation curve of $\mathrm{I}_{\mathrm{Na}}$ obtained in the absence (O) and presence (O) of $10 \mathrm{nM} \mathrm{GA}$. The normalized amplitude of $\mathrm{I}_{\mathrm{Na}}\left(\mathrm{I} / \mathrm{I}_{\max }\right)$ was constructed against the conditioning potential and the smooth curves were fitted by the Boltzmann equation (see text for details). Each point represents the mean \pm SEM $(n=5-9)$. The presence of GA produced a leftward shift in the inactivation curve of $I_{\mathrm{Na}}$ with no apparent change in the slope. 
A lack of GA effect on delayed rectifier $K^{+}$current $\left(I_{K(D R}\right)$

Further investigation was done to see if GA had any effect on $I_{\mathrm{K}(\mathrm{DR})}$. In these experiments, cells were bathed in $\mathrm{Ca}^{2+}$-free Tyrode's solution and the pipette was filled with a $\mathrm{K}^{+}$-containing solution, and $I_{\mathrm{K}(\mathrm{DR})}$ was elicited in response to different levels of depolarizing pulse. As can be seen in Fig. 9, unlike $I_{\mathrm{Na}}$, the $I_{\mathrm{K}(\mathrm{DR})}$ was not sensitive to blocking by GA (30 nM). Similarly, GA (10 $\mathrm{nM}$ ) had minimal effect on erg-mediated $\mathrm{K}^{+}$current in NG108-15 cells (data not shown).

\section{Effect of GA on spontaneous action potentials}

Another set of experiments was conducted to determine if GA exerted an effect on the spontaneous firing of APs in the cells. Current clamp conditions were established and the recording pipette was filled with $\mathrm{K}^{+}$-containing solution. As can be seen in Fig. 10, when the cells were exposed to GA (10 and $30 \mathrm{nM}$ ), both amplitude and frequency of spontaneous APs were progressively reduced. However, no apparent change in the resting membrane potential was seen in the presence of GA. The effect of GA on spontaneous APs can be explained primarily as a blocking of $I_{\mathrm{Na}}$.

\section{Discussion}

GA prolonged the latency to seizures and attenuated the seizure severity. That acute seizures and status epilepticus could be attenuated by GA, as well as the lack of correlation of severe seizures with IL- $1 \alpha$ and IL-1 $\beta$, suggested that GA could exert an acute effect that also seemed to be faster than typical anti-inflammatory action. The acute effect on seizures and status epilepticus, could possibly be related to sodium channel modulation. In contrast, the attenuation of chronic SRS and excitotoxicity, as well as the correlation between IL-1 $\alpha$

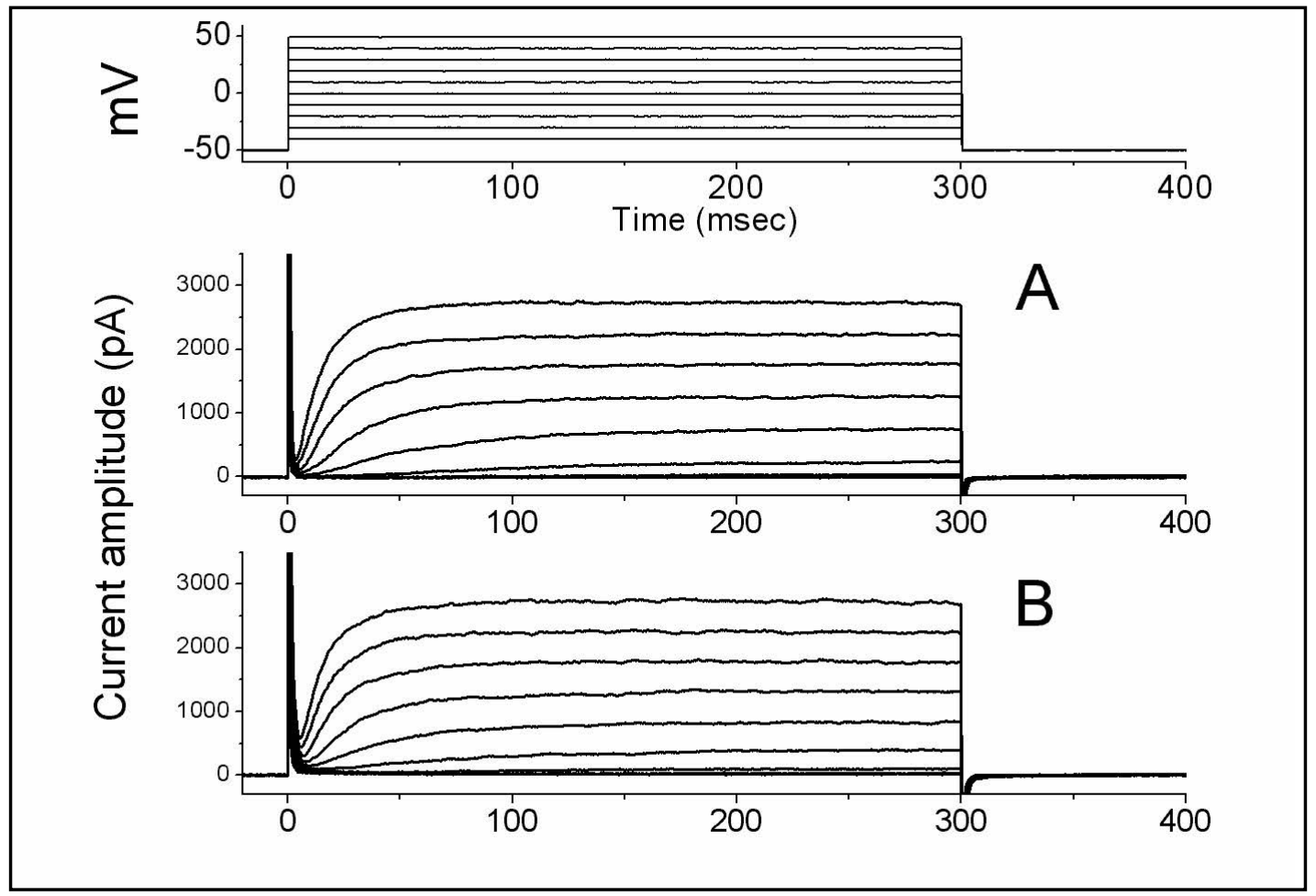

Fig. 9. GA could not alter the delayed-rectifier $\mathrm{K}^{+}$current $\left(\mathrm{I}_{\mathrm{K}(\mathrm{DR})}\right)$ in NG108-15 cells. Cells were bathed in $\mathrm{Ca}^{2+}$-free Tyrode's solution and the pipette was filled with a $\mathrm{K}^{+}$-containing solution. (A): control, (B): $30 \mathrm{nM}$ GA. The uppermost part shows the voltage protocol used. GA has little or no effect on $\mathrm{I}_{\mathrm{K}(\mathrm{DR})}$ in these cells. 


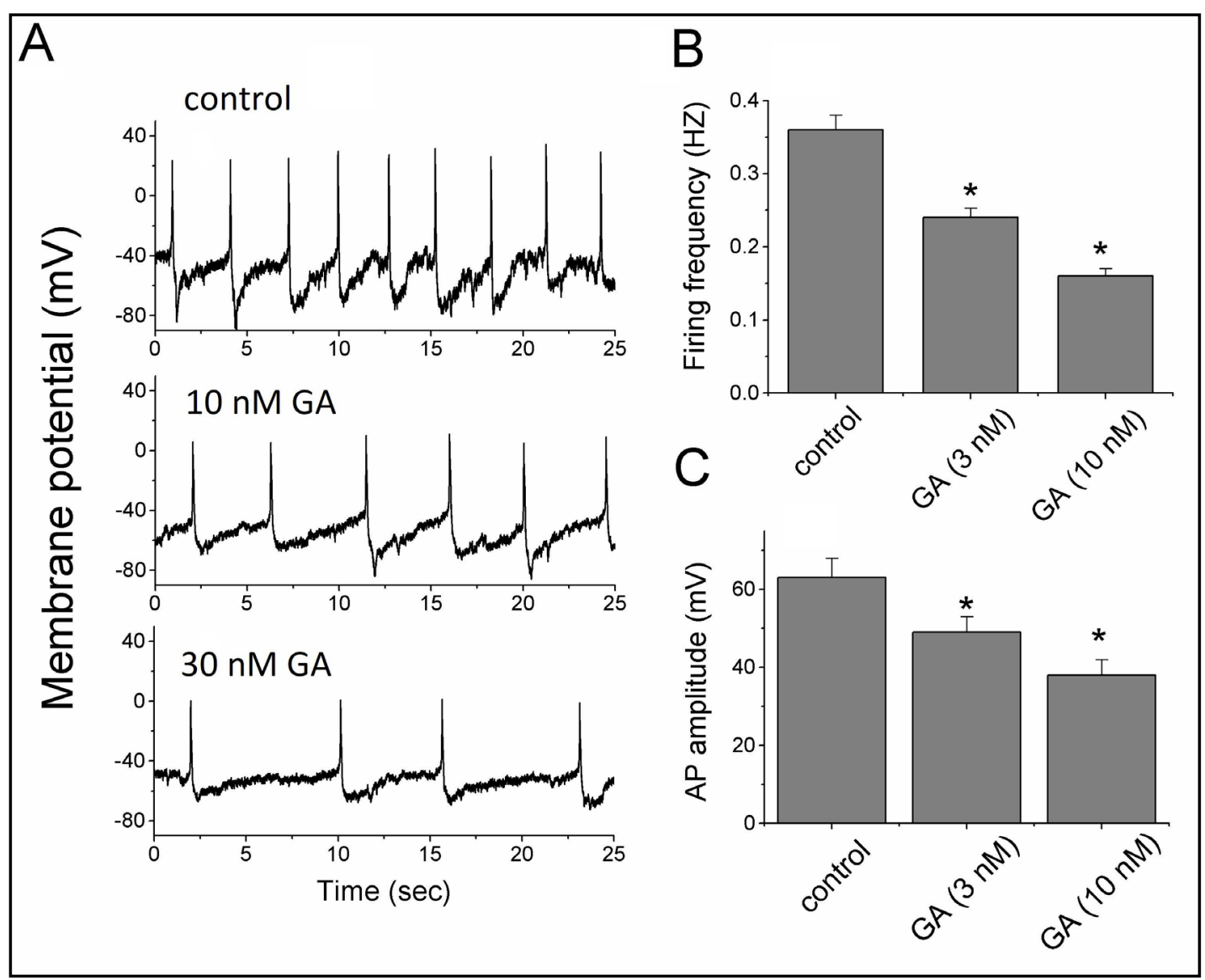

Fig. 10. The effect of GA on the spontaneous action potentials (APs) of NG108-15 cells. Cells were bathed in normal Tyrode's solution containing $1.8 \mathrm{mM} \mathrm{CaCl}_{2}$ and the pipette was filled with $\mathrm{K}^{+}$-containing solution. (A) Original potential traces obtained in the absence and presence of GA (control, $10 \mathrm{nM}$ GA and $30 \mathrm{nM} \mathrm{GA}$ ). The summary of data showing effects of GA on firing frequency and AP amplitude is illustrated in (B) and (C), respectively. Each point represents the mean \pm SEM $(n=6-11)$. *Significantly different from controls.

and chronic SRS, supports the hypothesis that GA affects sodium channel modulation and inflammation and has potential for the modification of epileptogenesis, as evidenced in our study.

The administration of GA before status epilepticus aims to evaluate the acute effect, which would relatively more relate to acute sodium channel-attenuation effect, instead of a chronic epileptogenesis-ameliorating effect. The regular daily administration of GA following status epilpeticus aimed to evaluate the effect of GA on epileptogenesis and chronic spontaneous recurrent seizures. Therefore, in our study, combining the effect of GA administered before and after status epilepticus, we know the overall attenuation of acute and chronic seizures were at least partially, related to both sodium channel attenuation and anti-inflammation.

Recent studies have shown that GA affects the IL-1 system [41]. In vitro experiments with T-cell contact-activated monocytes, a model relevant to chronic inflammation, showed that GA strongly reduced expression of IL- $1 \beta$ while enhancing the expression of sIL-1Ra. This is in contrast to the effects on monocytes subjected to acute inflammatory conditions (stimulation with LPS), where the presence of GA increased production of both sIL-1Ra and IL-1 $\beta$. It seems fair to conclude that the effects on the IL-1 system in chronic inflammatory conditions contribute to the therapeutic effects of GA in RRMS [41]. The existence of the different effects of GA between acute and chronic inflammatory states are also supported by our study. 


\section{Cellular Physiology Cell Physiol Biochem 2018;50:150-168

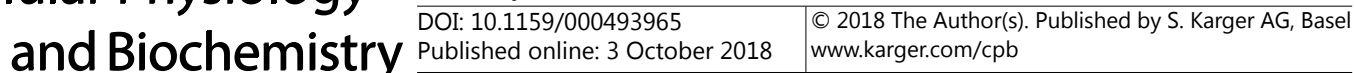

Lai et al.: Effect of Glatiramer Acetate on Epileptogenesis and Seizures

IL-1 $\alpha$ differs markedly from IL-1 $\beta$ not only in primary structure, but in the importance of its pro-segment. As a prototypical pro-inflammatory cytokine [42], IL-1 $\alpha$ appears to have bioactivity while in the form of an intact pro-cytokine. IL- $1 \beta$ but not IL- $1 \alpha$, is involved in T-cell-dependent antibody production [43]. The use of IL- $1 \alpha$ as a potential biomarker in epileptogenesis or epileptic seizures remains to be clarified by further investigation.

It has been reported TNF- $\alpha$ level was elevated in the acute stage following kainic acid injection [44] and TNF- $\alpha$ activated astrocytes can mediate astrocytic $\mathrm{Ca}^{2+}$-dependent glutamate release and contribute to excitotoxicity [45]. Interestingly, the similar TNF- $\alpha$ levels in the hippocampus of GA and control groups suggest the TNF- $\alpha$ is not a major role in the anti-epileptogenic effect of GA in the lithium-pilocarpine epilepsy modeling. The differential effect between TNF- $\alpha$ and IL- $1 \alpha$ in the role of epileptogenesis is worth further investigation.

GA can activate the non-selective cation current in which TRPA1 is predominantly encoded in Jurkat T lymphocytes. A current study [46] demonstrated that TPRA1-/- CD4+ $\mathrm{T}$ cells have increased T-cell receptor-induced $\mathrm{Ca}^{2+}$ influx, activation profile and subsequent differentiation into Th1-effector cells. The study suggests a protective role of TRPA1 in T-cellmediated colitis as well as activation by GA of a non-selective cation current in lymphocytes that could contribute to a decrease in IL- $\alpha$ production.

In some progressive neurological disorders, and under certain conditions, a GA neuroprotective response is seen before an adaptive immune response [47]. This again suggests that GA induced neuroprotection may be partly $\mathrm{T}$ cell independent. In primary human neurons intoxicated with staurosporine or reactive oxygen species, the direct effect of GA on neurons has been reported [48]. This T cell-independent neuroprotection is mediated by protein kinase $\mathrm{C}-\alpha$ and brain derived neurotrophic factor. Additionally, treatment was neuroprotective following optic nerve crush injury in athymic nude rats, further supporting a $\mathrm{T}$ cell-independent mechanism for GA action [49].

Voltage-gated sodium channels that play a major role in controlling neuronal excitability, have also demonstrated their importance during epileptogenesis [50,51]. In our study, the sodium channels in the differentiated NG108-15 cells are mainly due to Nav1.7 expression [39]. Other studies have provided evidence of a role of SCN9A which encodes Nav1.7 in human epilepsies [52], including febrile seizures plus and Dravet syndrome [53].

Mechanistically, GA reduced $I_{\mathrm{Na}}$ without altering $I-V$ relationship in the differentiated NG 108-15 cells. It suppressed the peak amplitude of $I_{\mathrm{Na}}$ in a concentration-dependent manner, with an $\mathrm{IC}_{50}$ value of $13 \mathrm{nM}$ and shifted the inactivation curve of $I_{\mathrm{Na}}$ to a hyperpolarized potential by approximately $10 \mathrm{mV}$. Nevertheless, GA had minimal effect on both the $I_{\mathrm{K}(\mathrm{DR})}$ and erg-mediated $\mathrm{K}^{+}$current in these cells. When cells were exposed to GA, both amplitude and frequency of spontaneous APs were progressively reduced. Our study clearly shows that GA can modulate neuronal excitability, at least partially, through effects on neuronal sodium channels.

The $I_{\mathrm{Na}}$ is thought to contain a "window" component that results from the overlap of its voltage-dependent activation and inactivation characteristics [54], ie, window $I_{\mathrm{Na}}$. This window current is comparable with the persistent $I_{\mathrm{Na}}$ in both peak amplitude and activation threshold. The steady-state inactivation curve of $I_{\mathrm{Na}}$ was shifted to a hyperpolarized potential in the presence of GA. Therefore, GA is likely to interact with the inactivated state of the $\mathrm{Na}_{\mathrm{v}}$ channels. Our study clearly showed that intracellular dialysis with $100 \mathrm{nM}$ GA did not affect the peak amplitude of $I_{\mathrm{Na}}$, this may have been because GA induced inhibition of $I_{\mathrm{Na}}$ had been taking place at a site accessible from the extracellular side of the channel. Whether the GA actions on $\mathrm{Na}_{\mathrm{v}}$ channels involve a concerted constriction of the outer part of the channel pore remains to be elucidated. Note that GA not only decreased the amplitude of $I_{\mathrm{Na}^{\prime}}$ but it also produced an approximately $10-\mathrm{mV}$ left shift in the inactivation curve of this current. However, the slope factor of the $I_{\mathrm{Na}}$ inactivation curve remained unaltered in the presence of GA. These results indicate that GA can shift the inactivation curve of $I_{\mathrm{Na}}$ in NG108-15 neurons, leading to a reduction of window $I_{\mathrm{Na}}$ :

An earlier study showed the ability of GA to induce sIL-1Ra expression via the activation of PI3K, AKt, MEK1/2, and ERK1/2 [55]. However, PD- 98059 (10 mM) was not found to 


\section{Cellular Physiology Cell Physiol Biochem 2018;50:150-168 \begin{tabular}{l|l} 
DOI: 10.1159/000493965 & Ond Biochemistry \\
Published online: 30ctober 2018 & $\begin{array}{l}\text { O 2018 The Author(s). Published by S. Karger AG, Basel } \\
\text { www.karger.com/cpb }\end{array}$
\end{tabular}}

Lai et al.: Effect of Glatiramer Acetate on Epileptogenesis and Seizures

have an effect on GA-induced inhibition of $I_{\mathrm{Na}}$ in NG108-15 cells. Therefore, it seems likely that this inhibition of $I_{\mathrm{Na}}$ is not associated with activation of MEK/ERK pathways. Potassium channels, especially $I_{\mathrm{K}(\mathrm{DR})}$, widely expressed in the brain and spinal cord, are critical in the regulation of neuronal excitability, axonal conduction, and neurotransmitter release $[56,57]$. Furthermore, two-pore domain potassium channel TASK1 (KCNK3) has been reported to be an important modulator in autoimmune CNS inflammation, such as multiple sclerosis. Nevertheless, our study did not demonstrate the direct involvement of GA in voltage-gated potassium currents.

It has been reported that GA could effectively attenuate allodynia and hyperalgesic responses in models of inflammatory pain, possibly through mechanisms involving the modulation of chemokine CX3CL1 4 [58]. In addition, it has been found that both sodium channels and transient receptor potential vanilloid receptor 1 (TRPV1) channels are involved in pain transmission mediated by nociceptive DRG neurons and the hyperalgesia related to upregulation of expression of TRPV1 and Nav1.8 channels. Some isoforms of the voltage-gated sodium channel alpha-subunit are implicated in inflammatory pain states, and they are expressed by somatosensory primary afferent neurons but not by skeletal or cardiovascular muscle [59].

Earlier reports have demonstrated the important differences between CA1 and CA3 hippocampal cells, including the more homogeneous group of cells in CA3 than the CA1 pyramidal cell population, and the difference in neuronal excitability, especially the calcium dependent potentials in the CA1 and CA3 hippocampal cells [60,61], as well as the subtle changes in the slow afterhyperpolarization (AHP) in CA1 but a marked reduction in spike frequency adaptation accompanied by a significant reduction in AHP in CA3 in an epilepsy model [62]. Our study also suggested the differential excitability profile between CA1 and CA3. The relatively more prominent excitotoxicity ameliorating effect of GA in CA3 than CA1 seems to be a unique effect of GA. Whether this difference is specifically related to GA's specific mechanisms warrants further investigation.

The incidence of seizure disorders in multiple sclerosis has been reported to exceed the incidence in the general population. Several studies have reported seizures occurring at the onset of multiple sclerosis [63]. The increased risk of seizures may reflect the effects of inflammation and provides a theoretical basis for the application of GA in the treatment of seizure disorders.

An earlier study reported that GA treatment leads to sustained expression of neurotrophins, especially the the brain-derived neurotrophic factor (BDNF). The BDNF elevation could be seen in both GA-induced T cells and CNS resident cells, including neurons and astrocytes, which suggests the effect of GA on neuroprotection and regeneration, in addition to anti-inflammation [64]. In addition, it has been reported that hippocampal fibroblast growth factor- 2 and BDNF overexpression could reduce neuronal loss, attenuate epileptogenesis-associated neuroinflammation and reduce spontaneous recurrent seizures [65]. These findings support our results in the current study. Interestingly, the expression of IL-1 beta was almost completely prevented after local supplementation of FGF- 2 and BDNF in the rat hippocampus after pilocarpine-induced status epilepticus [65].

Recent studies have shown the mammalian target of rapamycin (mTOR) pathway has emerged as a key player for proper neural network development, and it is involved in epileptogenesis triggered by both genetic or acquired factors. Interestingly, everolimus, as an immune-suppressor, inhibits mTOR signaling by reducing the phosphorylation of downstream mTOR effectos, has shown potential anti-epileptogenic activities [66-68]. Whether the potential effect of GA on epileptogenesis is involved in mTOR inhibition is worth clinical investigation. 


\section{Cellular Physiology Cell Physiol Biochem 2018;50:150-168

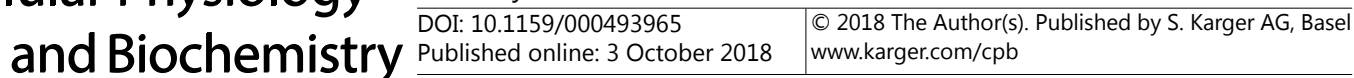

Lai et al.: Effect of Glatiramer Acetate on Epileptogenesis and Seizures

\section{Conclusion}

Our study showed that GA might serve as a neuroexcitability modulator, on the basis of its sodium channel attenuation, which seems to be independent of its inflammationmodulatory effect. This leads to a potential application of GA, for the treatment of epileptic seizures.

\section{Acknowledgements}

This study was partly funded by the Ministry of Science and Technology, Taiwan (Grant Nos. 105-2314-B-006-013-, 106-2314-B-006-034-, 106-2320-B-006-055-, 107-2314-B006-018- and 107-2320-B-006-019-), the National Cheng Kung University Hospital (Grant No. 20180254), and the Chi-Mei Medical Center (Grant No. CMNCKU10303).

\section{Disclosure Statement}

The authors declare no conflicts of interest.

\section{References}

1 Kwan P, Brodie MJ: Refractory epilepsy: mechanisms and solutions. Expert Rev Neurother 2006;6:397-406.

-2 Zeng LH, Rensing NR, Wong M: Developing Antiepileptogenic Drugs for Acquired Epilepsy: Targeting the Mammalian Target of Rapamycin (mTOR) Pathway. Mol Cell Pharmacol 2009;1:124-129.

-3 Granata T, Cross H, Theodore W, Avanzini G: Immune-mediated epilepsies. Epilepsia 2011;52:5-11.

$\checkmark 4$ Vezzani A, Granata T: Brain inflammation in epilepsy: Experimental and clinical evidence. Epilepsia 2005;46:1724-1743.

-5 Niquet J, Ben-Ari Y, Represa AA: Glial reaction after seizure induced by hippocampal lesion: immunohistochemical characterization of glial cells. J Neurocytol 1994;23:641-656.

6 Represa A, Niquet J, Pollard H, Ben-Ari Y: Cell death, gliosis, and synaptic remodeling in the hippocampus of epileptic rats. J Neurobiol 1995;26:413-425.

7 De Simoni MG, Perego C, Ravizza T, Moneta D, Conti M, Marchesi F, De Luigi A, Garattini S, Vezzani A: Inflammatory cytokines and related genes are induced in the rat hippocampus by limbic status epilepticus. Eur J Neurosci 2000;12:2623-2633.

-8 Dinarello CA: Interleukin-1 in the pathogenesis and treatment of inflammatory diseases. Blood 2011;117:3720-3732.

9 Wang S, Cheng $\mathrm{Q}$ Malik S, Yang J: Interleukin-1beta inhibits gamma-aminobutyric acid type A (GABA(A)) receptor current in cultured hippocampal neurons. J Pharmacol Exp Ther 2000;292:497-504.

-10 Viviani B, Bartesaghi S, Gardoni F, Vezzani A, Behrens MM, Bartfai T, Binaglia M, Corsini E, Di Luca M, Galli CL, Marinovich M: Interleukin-1beta enhances NMDA receptor-mediated intracellular calcium increase through activation of the Src family of kinases. J Neurosci 2003;23:8692-8700.

11 Vezzani A, Conti N, DeLuigi A, Ravizza T, Moneta D, Marchesi F, De Simoni MG: Interleukin-l beta immunoreactivity and microglia are enhanced in the rat hippocampus by focal kainate application: Functional evidence for enhancement of electrographic seizures. J Neurosci 1999;19:5054-5065.

12 Ziemssen T, Schrempf W: Glatiramer acetate: mechanisms of action in multiple sclerosis. Int Rev Neurobiol 2007;79:537-570.

13 Sela M: Poly(a-amino acids) -- From a better understanding of immune phenomena to a drug against multiple sclerosis. Acta Polym 1998;49:523-525.

-14 Aharoni R, Vainshtein A, Stock A, Eilam R, From R, Shinder V, Arnon R: Distinct pathological patterns in relapsing-remitting and chronic models of experimental autoimmune enchephalomyelitis and the neuroprotective effect of glatiramer acetate. J Autoimmun 2011;37:228-241. 


\section{Cellular Physiology Cell Physiol Biochem 2018;50:150-168

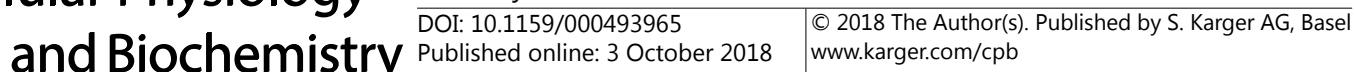

Lai et al.: Effect of Glatiramer Acetate on Epileptogenesis and Seizures

15 Angelov DN, Waibel S, Guntinas-Lichius O, Lenzen M, Neiss WF, Tomov TL, Yoles E, Palgi O, Kipnis J, Schori H, Reuter A, Ludolph A, Schwartz M: Therapeutic vaccine for acute and chronic motor neuron diseases: Implications for ALS. Proc Natl Acad Sci USA 2003;100:4790-4795.

16 Frenkel D, Maron R, Burt DS, Weiner HL: Nasal vaccination with a proteosome-based adjuvant and glatiramer acetate clears beta-amyloid in a mouse model of Alzheimer disease. J Clin Invest 2005;115:24232433.

17 Weber MS, Starck M, Wagenpfeil S, Meinl E, Hohlfeld R, Farina C: Multiple sclerosis: glatiramer acetate inhibits monocyte reactivity in vitro and in vivo. Brain 2004;127:1370-1378.

18 Kala M, Rhodes SN, Piao WH, Shi FD, Campagnolo DI, Vollmer TL: B cells from glatiramer acetate-treated mice suppress experimental autoimmune encephalomyelitis. Exp Neurol 2010;221:136-145.

-19 Vezzani A, Moneta D, Richichi C, Aliprandi M, Burrows SJ, Ravizza T, Perego C, De Simoni MG: Functional role of inflammatory cytokines and antiinflammatory molecules in seizures and epileptogenesis. Epilepsia 2002;43:30-35.

20 Mody I: Ion channels in epilepsy. Int Rev Neurobiol 1998;42:199-226.

21 Blumenfeld H: Cellular and network mechanisms of spike-wave seizures. Epilepsia 2005;46:s21-23.

22 Lerche H, Shah M, Beck H, Noebels J, Johnston D, Vincent A: Ion channels in genetic and acquired forms of epilepsy. J Physiol 2013;591:753-764.

23 Waszkielewicz AM, Gunia A, Szkaradek N, Słoczyńska K, Krupińska S, Marona H: Ion channels as drug targets in central nervous system disorders. Curr Med Chem 2013;20:1241-1285.

24 Stafstrom CE: The role of the subiculum in epilepsy and epileptogenesis. Epilepsy Curr 2005;4:121-129.

-25 Yan B, Li P: An integrative view of mechanisms underlying generalized spike-and-wave epileptic seizures and its implication on optimal therapeutic treatments. PloS One 2011;6:e22440.

-26 Huang CW, Cheng JT, Tsai JJ, Wu SN, Huang CC: Diabetic hyperglycemia aggravates seizures and status epilepticus-induced hippocampal damage. Neurotox Res 2009;15:71-81.

-27 Huang CW, Wu SN, Cheng JT, Tsai JJ, Huang CC: Diazoxide reduces status epilepticus neuron damage in diabetes. Neurotox Res 2010;17:305-316.

28 Huang CW, Chow JC, Tsai JJ, Wu SN: Characterizing the effects of Eugenol on neuronal ionic currents and hyperexcitability. Psychopharmacology (Berl) 2012;221:575-587.

-29 Maroso M, Balosso S, Ravizza T, Liu J, Aronica E, Iyer AM, Rossetti C, Molteni M, Casalgrandi M, Manfredi AA, Bianchi ME, Vezzani A: Toll-like receptor 4 and high-mobility group box-1 are involved in ictogenesis and can be targeted to reduce seizures. Nat Med 2010;16:413-419.

30 Racine RJ: Modification of seizure activity by electrical stimulation. II. Motor seizure. Electroencephalogr Clin Neurophysiol 1972;32:281-294.

-31 Curia G, Longo D, Biagini G, Jones RS, Avoli M: The pilocarpine model of temporal lobe epilepsy. The pilocarpine model of temporal lobe epilepsy. J Neurosci Methods 2008;172:143-157.

32 Lai MC, Hung TY, Lin KM, Sung PS, Wu SJ, Yang CS, Wu YJ, Jsai JJ, Wu SN, Huang CW: Sodium Metabisulfite: Effects on Ionic Currents and Excitotoxicity. Neurotox Res 2018;34:1-15.

-33 Chang YC, Huang AM, Kuo YM, Wang ST, Chang YY, Huang CC: Febrile seizures impair memory and cAMP response-element binding protein activation. Ann Neurol 2003;54:706-718.

34 Pitkanen A, Kharatishvili I, Nissinen J, McIntosh T: Posttraumatic epilepsy induced by lateral fluidpercussion brain injury in rats; in Pitkanen A, Schwartzkroin PA, Moshe SL (eds): Models of seizures and epilepsy, Elsevier Academic Press, Burlington, 2006, pp 465-476.

35 Holmes GL, Ben-Ari Y: Seizures in the developing brain: perhaps not so benign after all. Neuron 1998;21:1231-1234.

-36 Nirenberg M, Wilson S, Higashida H, Rotter A, Krueger K, Busis N, Ray R, Kenimer JG, Adler M: Modulation of synapse formation by cyclic adenosine monophosphate. Science 1983;222:794-799.

37 Meves H, Schwarz JR, Wulfsen I: Separation of M-like current and ERG current in NG108-15 cells. Br J Pharmacol 1999;127:1213-1223.

-38 Huang CW, Huang CC, Lin MW, Tsai JJ, Wu SN: The synergistic inhibitory effects of oxcarbazepine on voltage-gated sodium and potassium channels in NG108-15 neurons and modeled neurons. Int J Neuropsychopharmacol 2008;11:597-610.

-39 Kawaguchi A, Asano H, Matsushima K, Wada T, Yoshida S, Ichida S: Enhancement of sodium current in NG108-15 during neural differentiation is mainly due to an increase in $\mathrm{Na}_{\mathrm{v}} 1.7$ expression. Neurochem Res 2007;32:1469-1475. 


\section{Cellular Physiology Cell Physiol Biochem 2018;50:150-168 \begin{tabular}{ll|l} 
DOI: 10.1159/000493965 2018 & $\begin{array}{l}\text { O } 2018 \text { The Author(s). Published by S. Karger AG, Basel } \\
\text { www.karger.com/cpb }\end{array}$
\end{tabular}

Lai et al.: Effect of Glatiramer Acetate on Epileptogenesis and Seizures

40 Yeh PS, Wu SJ, Hung TY, Huang YM, Hsu CW, Sze CI, Hsieh YJ, Huang CW, Wu SN: Evidence for the inhibition by temozolomide, an imidazotetrazine family alkylator, of intermediate-conductance $\mathrm{Ca}^{2+}$-activated $\mathrm{K}^{+}$ channels in glioma cells. Cell Physiol Biochem 2016;38:1727-1742.

-41 Burger D, Molnarfi N, Weber MS, Brandt KJ, Benkhoucha M, Gruaz L, Chofflon M, Zamvil SS, Lalive PH: Glatiramer acetate increases IL-1 receptor antagonist but decreases T cell-induced IL-1beta in human monocytes and multiple sclerosis. Proc Natl Acad Sci USA 2009;106:4355-4359.

$\checkmark 42 \mathrm{Hu}$ J, Cotgreave IA: Differential regulation of gap junctions by proinflammatory mediators in vitro. J Clin Invest 1997;99:2312-2316.

-43 Nakae S, Asano M, Horai R, Iwakura Y: Interleukin-1 beta, but not interleukin-1 alpha, is required for T-celldependent antibody production. Immunology 2001;104:402-409.

44 Minami M, Kuraishi Y, Satoh M: Effects of kainic acid on messenger RNA levels of IL-1 beta, IL-6, TNF alpha and LIF in the rat brain. Biochem Biophys Res Commun 1991;176:593-598.

45 Bezzi P, Domercq M, Brambilla L, Galli R, Schols D, De Clercq E, Vescovi A, Bagetta G, Kollias G, Meldolesi J, Volterra A: CXCR4-activated astrocyte glutamate release via TNFalpha: amplification by microglia triggers neurotoxicity. Nat Neurosci 2001;4:702-710.

46 Bertin S, Aoki-Nonaka Y, Lee J, de Jong PR, Kim P, Han T, Yu T, To K, Takahashi N, Boland BS, Chang JT, Ho SB, Herdman S, Corr M, Franco A, Sharma S, Dong H, Akopian AN, Raz E: The TRPA1 ion channel is expressed in CD4+ T cells and restrains T-cell-mediated colitis through inhibition of TRPV1. Gut 2017;66:1584-1596.

47 Kipnis J, Nevo U, Panikashvili D, Alexandrovich A, Yoles E, Akselrod S, Shohami E, Schwartz M: Therapeutic vaccination for closed head injury. J Neurotrauma 2003;20:559-569.

48 Liu J, Johnson TV, Lin J, Ramirez SH, Bronich TK, Caplan S, Persidsky Y, Gendelman HE, Kipnis J: T cell independent mechanism for copolymer-1-induced neuroprotection. Eur J Immunol 2007;37:3143-3154.

$\$ 49$ Kipnis J, Yoles E, Schori H, Hauben E, Shaked I, Schwartz M: Neuronal survival after CNS insult is determined by a genetically encoded autoimmune response. J Neurosci 2001;21:4564-4571.

$\checkmark 50$ Hargus NJ, Nigam A, Bertram EH 3rd, Patel MK: Evidence for a role of Nav1.6 in facilitating increases in neuronal hyperexcitability during epileptogenesis. J Neurophysiol 2013;110:1144-1157.

-51 Ashraf MN, Gavrilovici C, Shah SU, Shaheen F, Choudhary MI, Rahman AU, Fahnestock M, Simjee SU, Poulter MO: A novel anticonvulsant modulates voltage-gated sodium channel inactivation and prevents kindlinginduced seizures. J Neurochem 2013;126:651-661.

52 Singh NA, Pappas C, Dahle EJ, Claes LR, Pruess TH, De Jonghe P, Thompson J, Dixon M, Gurnett C, Peiffer A, White HS, Filloux F, Leppert MF: A role of SCN9A in human epilepsies, as a cause of febrile seizures and as a potential modifier of Dravet syndrome. PLoS Genet 2009;5:e1000649.

53 Mulley JC, Hodgson B, McMahon JM, Iona X, Bellows S, Mullen SA, Farrell K, Mackay M, Sadleir L, Bleasel A, Gill D, Webster R, Wirrell EC, Harbord M, Sisodiya S, Andermann E, Kivity S, Berkovic SF, Scheffer IE, Dibbens LM: Role of the sodium channel SCN9A in genetic epilepsy with febrile seizures plus and Dravet syndrome. Epilepsia 2013;54:e122-126.

-54 Wu SN, Chen BS, Lin MW, Liu YC: Contribution of slowly inactivating potassium current to delayed firing of action potentials in NG108-15 neuronal cells: experimental and theoretical studies. J Theor Biol 2008;252:711-721.

55 Carpintero R, Brandt KJ, Gruaz L, Molnarfi N, Lalive PH, Burger D: Glatiramer acetate triggers PI3Kd/Akt and MEK/ERK pathways to induce IL-1 receptor antagonist in human monocytes. Proc Natl Acad Sci USA 2010;107:17692-17697.

-56 Baranauskas G: Ionic channel function in action potential generation: current perspective. Mol Neurobiol 2007;35:129-150.

57 Benarroch EE: Potassium channels: Brief overview and implications in epilepsy. Neurology 2009;72:664669.

58 Sharma N, Thomas S, Ho L, Reyes DC, Sacerdote P, Bianchi M, Pasinetti GM: Immunomodulation with glatiramer acetate prevents long-term inflammatory pain. Int J Neurosci 2008;118:433-453.

59 Amir R, Argoff CE, Bennett GJ, Cummins TR, Durieux ME, Gerner P, Gold MS, Porreca F, Strichartz GR: The role of sodium channels in chronic inflammatory and neuropathic pain. J Pain 2006; 7:S1-29.

-60 Schwartzkroin PA, Prince DA: Effects of TEA on hippocampal neurons. Brain Res 1980;185:169-181.

61 Schwartzkroin PA, Stafstrom CE: Effects of EGTA on calcium-activated afterhyperpolarization in hippocampal CA3 pyramidal cells. Science 1980;210:1125-1126. 


\section{Cellular Physiology Cell Physiol Biochem 2018;50:150-168 \begin{tabular}{ll|l} 
DOI: 10.1159/000493965 & $\begin{array}{l}\text { O 2018 The Author(s). Published by S. Karger AG, Basel } \\
\text { www.karger.com/cpb }\end{array}$ \\
\hline
\end{tabular}}

Lai et al.: Effect of Glatiramer Acetate on Epileptogenesis and Seizures

62 Verma-Ahuja S, Evans MS, Pencek TL: Evidence for decreased calcium dependent potassium conductance in hippocampal CA3 neurons of genetically epilpeys-prone rats. Epilepsy Res 1995;22:137-144.

63 Marrie RA, Reider N, Cohen J, Trojano M, Sorensen PS, Cutter G, Reingold S, Stuve O: A systematic review of the incidence and prevalence of sleep disorders and seizure disorders in multiple sclerosis. Mult Scler 2015;21:342-349.

64 Aharoni R, Eilam R, Domev H, Labunskay G, Sela M, Arnon R: The immunomodulator glatiramer acetate augments the expression of neurotrophic factors in brains of experimental autoimmune encephalomyelitis mice. Proc Natl Acad Sci USA 2005;102:19045-19050.

-65 Bovolenta R, Zucchini S, Paradiso B, Rodi D, Merigo F, Navarro Mora G, Osculati F, Berto E, Marconi P, Marzola A, Fabene PF, Simonato M: Hippocampal FGF-2 and BDNF overexpression attenuates epileptogenesis-associated neuroinflammation and reduces spontaneous recurrent seizures. J Neuroinflammation 2010;7:81.

66 Krueger DA, Wilfong AA, Mays M, Talley CM, Agricola K, Tudor C, Capal J, Holland-Bouley K, Franz DN: Longterm treatment of epilepsy with everolimus in tuberous sclerosis. Neurology 2016;87:1-8.

67 Vezzani A: Before epilepsy unfolds: finding the epileptogenesis switch. Nat Med 2012;18:1626-1627.

68 Curatolo P, Moavero R, van Scheppingen J, Aronica E: mTOR dysregulation and tuberous sclerosis-related epilepsy. Expert Rev Neurother 2018;18:185-201. 